\title{
Mathematical modeling of ferrous sulfate oxidation in presence of air
}

\author{
Juan Carlos Beltrán-Prieto, ${ }^{1, *}$, and Karel Kolomazník ${ }^{1}$ \\ ${ }^{1}$ Faculty of Applied Informatics, Tomas Bata University in Zlín, nám. T. G. Masaryka 5555, 76001 Zlín, Czech Republic
}

\begin{abstract}
In the present paper we studied the oxidation of ferrous sulfate salt with oxygen. ferric ammonium sulfate and ferrous sulfate were used to prepare standard solutions of $\mathrm{Fe}(\mathrm{III})$ and $\mathrm{Fe}(\mathrm{II})$ solutions. Oxidation experiments were carried out by mixing $\mathrm{FeSO}_{4} \cdot 7 \mathrm{H}_{2} \mathrm{O}$ in $\mathrm{H}_{2} \mathrm{O}$. Air was supplied using a gas washing bottle in which air entered the bottle through the center tube, and exited into the bottom of the bottle. Samples were taken periodically and analyzed in the UV-Vis spectrophotometer. We consider that basic Fe(III) sulfate was one of the main compounds produced during the reaction and proposed a model to describe the process. We found solution to the differential equations that described the profile of $\mathrm{FeSO}_{4}$ and $\mathrm{FeOHSO}_{4}$ concentration in time and observed agreement between the experimental results and data predicted by the model. Moreover, we determined values of rate constants using the model and confirmed the determined values by means of experiments. This suggests that basic ferric sulfate was generated after aeration of ferrous sulfate solution.
\end{abstract}

\section{Introduction}

Ferrous sulfate $\left(\mathrm{FeSO}_{4}\right)$ is a compound that participates in a diversity of chemical reactions and processes, such as reducing agent or as colorant in dying and tannery industry, additionally, is generally used to treat iron deficiency. It is stable at normal conditions of pressure and temperature, it can be present in several hydrated forms, which upon contact with dry air lose water, it can be oxidize to ferric sulfate in presence of water. In a molecule of ferrous sulfate, $36.7 \%$ corresponds to iron metal. Iron can be found in soluble form in water as $\mathrm{Fe}(\mathrm{II})$ or $\mathrm{Fe}(\mathrm{OH})^{+}$or as a complex as in $\mathrm{Fe}(\mathrm{III})$ or $\mathrm{Fe}(\mathrm{OH})_{3}$. The presence of these compounds in drinking water causes a problem because it gives reddish color, bad odor, unpleasant taste and clogging [1-3].For these reasons, several attempts have been reported concerning the separation of iron from solutions containing ferrous sulfate, namely electrocoagulation, ion exchange, ultra filtration and oxidation.

The oxidation of ferrous sulfate generally leads to ferric sulfate in many cases. However, according to Reedy and Machin, ferrous sulfate is not completely oxidized easily to ferric sulfate in presence of air as experimental data demonstrates that the rate of reaction decreases very rapidly requiring extremely long time for complete oxidation ${ }^{4}$. Research has also been performed using air in a hot solution of ferrous sulfate with precipitation of iron as basic sulfate. During the process, poor soluble compounds such as $\mathrm{Fe}$ (III) oxides are formed. Moreover, it has been reported that the concentration of ferrous sulfate affects slightly the reaction rate. The reaction is favored in neutral $\mathrm{pH}$ and high temperature. The precipitated salts are mainly basic salts, such as basic ferric sulfate and ferric hydroxide [4]. Tolchev et al., reported the precipitation of iron (III) oxides by addition of oxidants at specific conditions of $\mathrm{pH}$, concentration, temperature, activity, feed rate and salts anion nature using hydrogen peroxide [5]. From all of these factors there is still diversity on opinions about which one are the most important for improving the oxidation rate and formation of oxides. It has been reported that in case of acid solutions, the addition of calcium hydroxide has increased the oxidation rate, as well as the use of air that provides $\mathrm{O}_{2}$ transfer and supports the oxidation of iron (II) to iron (III) [6]. The formation of ferric hydroxide has been also reported to catalyze the oxidation at lower $\mathrm{pH}$ values [7]. Additionally, studies have also been performed about the analysis of the morphological properties of iron oxides and oxohydroxide particles in which the shapes and sizes of particles grown from solutions under different conditions used during the precipitation method, namely $\mathrm{pH}$ adjustment, mixing and reaction temperature [8]. It is also important to consider that it has been challenging to predict accurately the precise effect of these parameters. Therefore, a better comprehension of the effect of these variables during the oxidation, precipitation process, compounds formed and morphology of iron oxides is needed [8-9]. The oxidation of ferrous ions in concentrated solutions of $\mathrm{H}_{2} \mathrm{SO}_{4}-\mathrm{FeSO}_{4}$ was studied in a

* Corresponding author: prieto@fai.utb.cz

(C) The Authors, published by EDP Sciences. This is an open access article distributed under the terms of the Creative Commons Attribution License 4.0 (http://creativecommons.org/licenses/by/4.0/). 
pressurized autoclave under isothermal and isobaric conditions [10] showing that temperature and pressure affect the oxidation rate. Kinetic parameters were estimated with nonlinear regression and the experimental data fitted properly to simulated values. During the oxidation procedure, four electrones are transfered from $\mathrm{Fe}^{2+}$ ions to one molecule of oxygen. A mechanism for the oxidation in aqueous phase involving a peroxide ion as an intermediate was studied by Sykes [11]. Accordingly, iron peroxides complexes were reported by Wang et al [12] using in situ FTIR by the contact of $\mathrm{H}_{2-}$ $\mathrm{O}_{2}$ of $\mathrm{N}_{2} \mathrm{O}$ with Fe-Al-P-O catalyst prepared by a sol-gel method.

The reaction mechanism is the quantitative description of the dependences of the reaction rates on the concentration of the reacting components. The description is generally explained using vector differential equation, which solutions are time dependent of the concentrations of the oxidation intermediate products [13-15]. In some cases, the chemical reactions are accompanied by various relatively complex simultaneous reactions resulting in a complicated blend of intermediate products. The oxidation of ferrous sulfate salt with oxygen can be modeled according to equation (1) in which basic Fe(III) sulfate is formed. The equation that describes the variation of concentration of $C_{i}$ at time $\tau$ is described in (2)

$$
\begin{gathered}
2 \mathrm{FeSO}_{4}+\frac{1}{2} \mathrm{O}_{2}+\mathrm{H}_{2} \mathrm{O} \vec{k} 2 \mathrm{FeOHSO}_{4} \\
-\frac{\mathrm{dC}_{\mathrm{i}}}{\mathrm{d} \tau}=\mathrm{kC}_{\mathrm{i}}{ }^{2}
\end{gathered}
$$

where $C_{i}$ is the concentration of $\mathrm{FeSO}_{4}$ at time $\tau, C_{p i}$ is the initial concentration of $\mathrm{FeSO}_{4}$, and $C_{f}$ is the concentration of $\mathrm{FeOHSO}_{4}$ at time $\tau$. Solution of equation (2) is presented in equations (3) to (6):

$$
\begin{gathered}
-\int_{C_{p i}}^{C_{i}} \frac{d C_{i}}{C_{i}{ }^{2}}=k \int_{0}^{\tau} d \tau \\
\frac{1}{C_{i}}-\frac{1}{C_{p i}}=k \tau \\
C_{i}=\frac{1}{k \tau+\frac{1}{C_{p i}}} \\
C_{i}=\frac{C_{p i}}{k \tau C_{p i}+1}
\end{gathered}
$$

The equation that describes the variation of concentration of $C_{f}$ at time $\tau$ is given in (7)

$$
\frac{d C_{f}}{d \tau}=k\left(C_{p i}-C_{f}\right)^{2}
$$

which solution leads to:

$$
\int \frac{d C_{f}}{\left(C_{p i}-C_{f}\right)^{2}}=k \int d \tau
$$

$$
\begin{gathered}
\left.\frac{1}{C_{p i}-C_{f}}\right|_{0} ^{C_{f}}=k \tau \\
\frac{1}{C_{p i}-C_{f}}-\frac{1}{C_{p i}}=k \tau \\
\frac{C_{f}}{C_{p i}\left(C_{p i}-C_{f}\right)}=k \tau \\
C_{f}=\frac{k \tau C_{p i}{ }^{2}}{1+k \tau C_{p i}}
\end{gathered}
$$

\section{Experimental part}

\subsection{Chemicals and instruments.}

$\mathrm{FeSO}_{4} \cdot 7 \mathrm{H}_{2} \mathrm{O}$ of technical grade required for the experimental part, was obtained from PENTA s.r.o.(Czech Republic). Deionized water was used in all procedures (Millipore). Helios Alpha UVVis spectrophotometer from Thermo Fisher was used for iron quantification.

\subsection{Methods.}

Fe(III) standard solution was prepared by mixing $2.41 \mathrm{~g}$ of ferric ammonium sulfate with $20 \mathrm{~mL}$ of $\mathrm{H}_{2} \mathrm{SO}_{4}$, transferred into a $500 \mathrm{~mL}$ volumetric flask and filled up with deionized water. Accordingly, Fe(II) standard solutions were prepared using $\mathrm{FeSO}_{4} \cdot 7 \mathrm{H}_{2} \mathrm{O}$. Dilutions were prepared from the respective stock solutions and absorbance at $400 \mathrm{~nm}$ was recorded. Oxidation experiments were carried out by mixing $19.46 \mathrm{~g}$ of FeSO $4 \cdot 7 \mathrm{H}_{2} \mathrm{O}$ in $100 \mathrm{~mL} \mathrm{H}_{2} \mathrm{O}$. Then air was supplied using a gas washing bottle in which air entered the bottle through the center tube, and exited into the bottom of the bottle. Samples were taken periodically every 30 minutes and analyzed in the UV-Vis spectrophotometer.

\section{Results}

The summary of results is presented in Table 1 describing the variation of Fe (III) concentration of each sample. Experimental results were compared to modeling data obtained from equations (6) and (12) and comparison is showed in Figure 1. As can be seen, the concentration of $\mathrm{Fe}$ (III) increases over time and the concentration remain stable after $2 \mathrm{~h}$ of aeration and agreement between experimental results and model was observed. Additionally, dimensionless values of concentration for experimental and mathematical model were calculated and are presented in Table 2. 
Table 1. Summary of experimental data

\begin{tabular}{|c|c|c|c|}
\hline Time (h) & $\begin{array}{c}\text { Absorbance } \\
\text { at } \mathbf{4 0 0} \mathbf{~ n m}\end{array}$ & $\begin{array}{c}\text { concentration } \\
(\mathbf{m g} / \mathbf{m L}) \mathbf{F e}^{+3}\end{array}$ & $\begin{array}{c}\mathbf{C}_{\mathbf{f}}=\text { mass of } \\
\mathbf{F e}^{+3} \text { in } \\
\text { reaction } \\
\text { blend (g) }\end{array}$ \\
\hline 0 & 0,486 & 0,000 & 0,000 \\
\hline 0,5 & 0,914 & 0,050 & 4,604 \\
\hline 1 & 1,091 & 0,070 & 6,211 \\
\hline 1,5 & 1,372 & 0,103 & 8,711 \\
\hline 2 & 1,419 & 0,109 & 8,345 \\
\hline 2,5 & 1,563 & 0,125 & 8,743 \\
\hline 3 & 1,658 & 0,137 & 8,647 \\
\hline
\end{tabular}

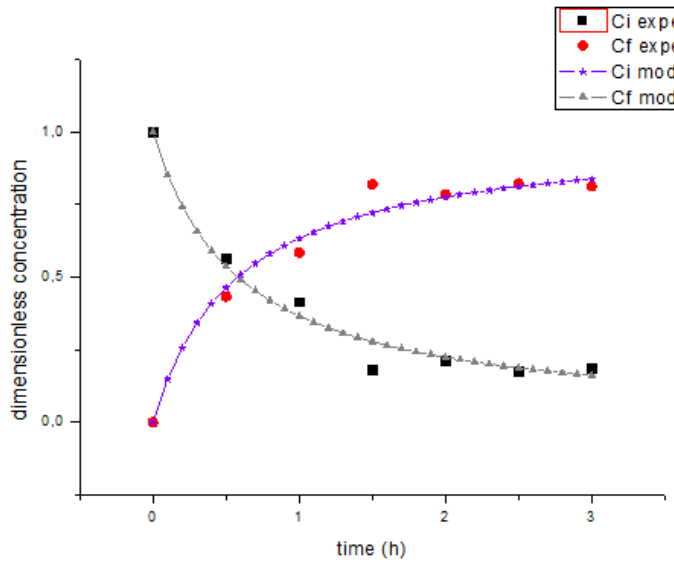

Fig. 1. Comparison of experimental and numerical data for the oxidation of $\mathrm{FeSO}_{4}$ to $\mathrm{Fe}(\mathrm{OH}) \mathrm{SO}_{4}$ in the presence of air.

Table 2. Dimensionless values of concentration (experimental and from mathematical model)

\begin{tabular}{|c|c|c|c|}
\hline $\begin{array}{c}\mathbf{C}_{\mathbf{i}} / \mathbf{C p}_{\mathbf{i}} \\
(\mathbf{e x p})\end{array}$ & $\begin{array}{c}\mathbf{C}_{\mathbf{i}} \\
(\mathbf{m o d e l})\end{array}$ & $\begin{array}{c}\mathbf{C}_{\mathbf{f}} / \mathbf{C}_{\mathbf{p i}} \\
(\mathbf{e x p})\end{array}$ & $\begin{array}{c}\mathbf{C}_{\mathbf{f}} \\
(\mathbf{m o d e l})\end{array}$ \\
\hline 1,000 & 1,000 & 0,000 & 0,000 \\
\hline 0,567 & 0,536 & 0,433 & 0,464 \\
\hline 0,416 & 0,366 & 0,584 & 0,634 \\
\hline 0,181 & 0,278 & 0,819 & 0,722 \\
\hline 0,215 & 0,224 & 0,785 & 0,776 \\
\hline 0,178 & 0,188 & 0,822 & 0,812 \\
\hline 0,187 & 0,162 & 0,813 & 0,838 \\
\hline
\end{tabular}

The value of rate constant $k$ can be determined using equation (12) or (6), which corresponds to $k=1.73$. Accordingly, this value can be also calculated using linearization of equation (6) as shown next

$$
\frac{1}{C_{i}}=\frac{k \tau C_{p i}+1}{C_{p i}}
$$

$$
\frac{1}{C_{i}}=k \tau+\frac{1}{C_{p i}}
$$

Which corresponds to the linear equation $\mathrm{y}=\mathrm{mx}+\mathrm{b}$, where $\mathrm{y}=\frac{1}{\mathrm{C}_{\mathrm{i}}}, \mathrm{m}=\mathrm{k}$, and $\mathrm{b}=\frac{1}{\mathrm{C}_{\mathrm{pi}}}$. Therefore: $\mathrm{y}=$ $1.64 x+0.99$. From here, the value of $k=1.64$, which is similar to the numerical value previously calculated of 1.73. The value of $C_{p i}$ is calculated from $0.99=1 / \mathrm{C}_{\mathrm{pi}}$. Therefore $\mathrm{C}_{\mathrm{pi}}=\frac{1}{0.99}=1.01$, which corresponds to the real value of 1 .

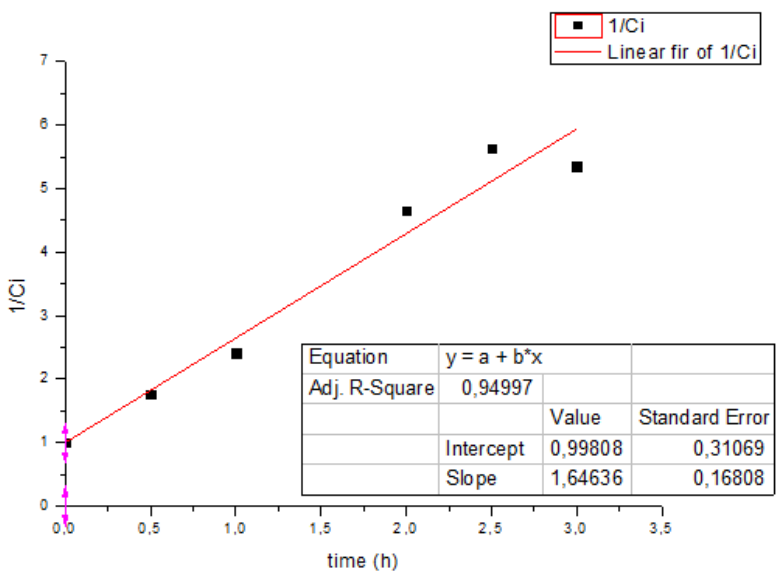

Fig. 2. Linear plot of the equation that describes the variation of concentration $C_{i}$ in time $\tau$

A similar procedure can be performed using linearization of equation (12). We obtain first the inverse:

$$
\begin{aligned}
& \frac{1}{C_{f}}=\frac{1+k C_{p i} \tau}{k C_{p i}{ }^{2} \tau} \\
& \frac{1}{C_{f}}=\frac{1}{k \tau C_{p i}{ }^{2}}+\frac{k \tau C_{p i}}{k \tau C_{p i}{ }^{2}} \\
& \frac{1}{C_{f}}=\frac{1}{k C_{p i}{ }^{2} \tau}+\frac{1}{C_{p i}}
\end{aligned}
$$

Multiplying by $\tau$ :

$$
\begin{aligned}
\frac{\tau}{C_{f}} & =\frac{\tau}{k C_{p i}{ }^{2} \tau}+\frac{\tau}{C_{p i}} \\
\frac{\tau}{C_{f}} & =\frac{1}{k C_{p i}{ }^{2}}+\frac{1}{C_{p i}} \tau
\end{aligned}
$$

Which corresponds to the linear equation $y=b+m x$, where $y=\frac{\tau}{C_{f}}, b=\frac{1}{k C_{p i}{ }^{2}}$, and $m=\frac{1}{C_{p i}}$ 


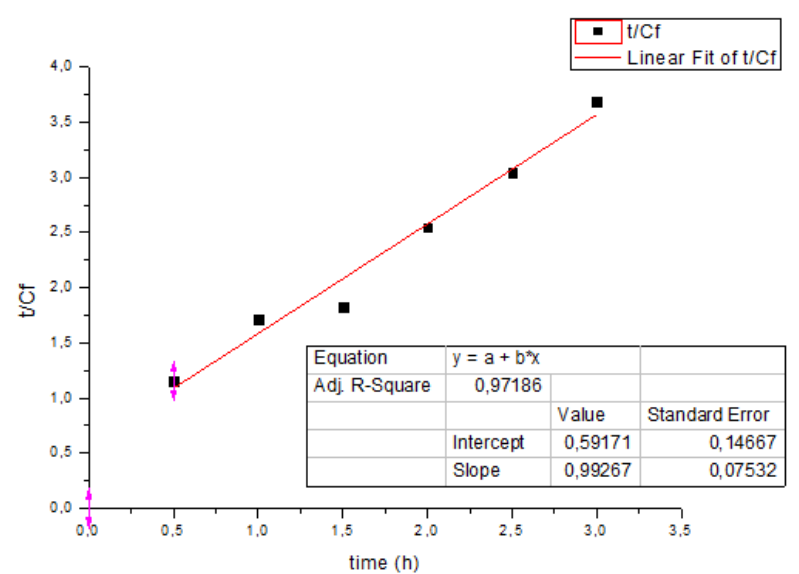

Fig. 3. Linear plot of the equation that describes the variation of concentration $C_{f}$ in time $\tau$

Therefore the equation corresponds to $y=0.592+$ $0.993 x, \frac{\tau}{C_{f}}=\frac{1}{k C_{p i}{ }^{2}}+\frac{1}{C_{p i}} \tau$. Since $C_{p i}=1$ (dimensionless value) it can be proved that: $\frac{1}{C_{p i}}=0.993$ and: $\frac{1}{k C_{p i}{ }^{2}}=$ 0.592. As a result, $k=\frac{1}{0.592}$ and $k=1.69$. Which corresponds to the value calculated previously of $k=1.73$.

\section{Conclusions}

In the present paper, we aimed to study the oxidation of ferrous sulfate salt with oxygen. We proposed that one possible compound is basic Fe(III) sulfate. We solved the differential equations that describe the profile of $\mathrm{FeSO}_{4}$ and $\mathrm{FeOHSO}_{4}$ concentration in time. We observed agreement between the experimental data and the results predicted by the model. Moreover, the values of rate constant calculated from both methods were very approximate. These results confirm that basic ferric sulfate is generated after aeration of ferrous sulfate solution. This information could be important for getting a better understanding about the reaction mechanism in oxidation reactions and in purification steps.

This work was supported by the Ministry of Education, Youth and Sports of the Czech Republic within the National Sustainability Programme project No. LO1303 (MSMT7778/2014).

\section{References}

1. S. Chaturvedi and P.N. Dave, Desalination 303, 1 (2012).

2. B.-Y. Cho, Process Biochem. 40, 3314 (2005).

3. N. Khatri, S. Tyagi, and D. Rawtani, J. Water Process Eng. 19, 291 (2017).

4. J.H. Reedy and J.S. Machin, Ind. Eng. Chem. 15, 1271 (1923).

5. A.V. Tolchev, D.G. Kleschov, R.R. Bagautdinova, and V.Y. Pervushin, Mater. Chem. Phys. 74, 336 (2002).
6. S.P. Burke and S.A. Banwart, Appl. Geochemistry 17, 431 (2002).

7. H.Z. Sarikaya, Water Res. 24, 329 (1990).

8. C. Domingo, R. Rodríguez-Clemente, and M. Blesa, J. Colloid Interface Sci. 165, 244 (1994).

9. M.J. Ryan, A.D. Kney, and T.L. Carley, Appl. Geochemistry 79, 27 (2017).

10. M.R. Rönnholm, J. Wärnå, T. Salmi, I. Turunen, and M. Luoma, Chem. Eng. Sci. 54, 4223 (1999).

11. A.G. Sykes, Kinetics of Inorganic Reactions, Pergamon, (1966).

12. Y. Wang, K. Otsuka, and K. Ebitani, Catal. Letters 35, 259 (1995).

13. A. S. Foust, L. A. Wenzel, C. W. Clump, L. Maus, and L. B. Andersen, Principles of unit operations, John Wiley \& Sons, Inc, New Delhi, (1980).

14. I. Tosun, Modeling in Transport Phenomena, (Elsevier, 2007).

15. B. A. Finlayson, Introduction to Chemical Engineering Computing. John Wiley and Sons, Inc, (2006). 